\title{
International consensus on use of continuous glucose monitoring
}

Danne, Thomas; Nimri, Revital; Battelino, Tadej; Bergenstal, Richard M.; Close, Kelly L.; DeVries, J. Hans; Garg, Satish; Heinemann, Lutz; Hirsch, Irl; Amiel, Stephanie A.; Beck, Roy; Bosi, Emanuele; Buckingham, Bruce; Cobelli, Claudio; Dassau, Eyal; Doyle, Francis J.; Heller, Simon; Hovorka, Roman; Jia, Weiping; Jones, Tim; Kordonouri, Olga; Kovatchev, Boris; Kowalski, Aaron; Laffel, Lori; Maahs, David; Murphy, Helen R.; Nørgaard, Kirsten; Parkin, Christopher G.; Renard, Eric; Saboo, Banshi; Scharf, Mauro; Tamborlane, William V.; Weinzimer, Stuart A.; Phillip, Moshe

Published in:

Diabetes Care

DOI:

$10.2337 / \mathrm{dc} 17-1600$

Publication date:

2017

Document version

Publisher's PDF, also known as Version of record

Document license:

Other

Citation for published version (APA):

Danne, T., Nimri, R., Battelino, T., Bergenstal, R. M., Close, K. L., DeVries, J. H., Garg, S., Heinemann, L., Hirsch, I., Amiel, S. A., Beck, R., Bosi, E., Buckingham, B., Cobelli, C., Dassau, E., Doyle, F. J., Heller, S., Hovorka, R., Jia, W., ... Phillip, M. (2017). International consensus on use of continuous glucose monitoring. Diabetes Care, 40(12), 1631-1640. https://doi.org/10.2337/dc17-1600 


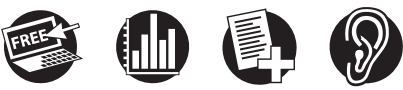

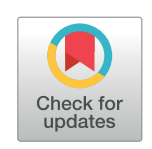

\section{International Consensus on Use of Continuous Glucose Monitoring}

Diabetes Care 2017;40:1631-1640 | https://doi.org/10.2337/dc17-1600

\begin{abstract}
Measurement of glycated hemoglobin $\left(\mathrm{HbA}_{1 \mathrm{c}}\right)$ has been the traditional method for assessing glycemic control. However, it does not reflect intra- and interday glycemic excursions that may lead to acute events (such as hypoglycemia) or postprandial hyperglycemia, which have been linked to both microvascular and macrovascular complications. Continuous glucose monitoring (CGM), either from real-time use (rtCGM) or intermittently viewed (iCGM), addresses many of the limitations inherent in $\mathrm{HbA}_{1 \mathrm{c}}$ testing and self-monitoring of blood glucose. Although both provide the means to move beyond the $\mathrm{HbA}_{1 \mathrm{c}}$ measurement as the sole marker of glycemic control, standardized metrics for analyzing CGM data are lacking. Moreover, clear criteria for matching people with diabetes to the most appropriate glucose monitoring methodologies, as well as standardized advice about how best to use the new information they provide, have yet to be established. In February 2017, the Advanced Technologies \& Treatments for Diabetes (ATTD) Congress convened an international panel of physicians, researchers, and individuals with diabetes who are expert in CGM technologies to address these issues. This article summarizes the ATTD consensus recommendations and represents the current understanding of how CGM results can affect outcomes.
\end{abstract}

Glucose measurements are critical to effective diabetes management. Although measurement of glycated hemoglobin $\left(\mathrm{HbA}_{1 \mathrm{c}}\right)$ has been the traditional method for assessing glycemic control, it does not reflect intra- and interday glycemic excursions that may lead to acute events (such as hypoglycemia) or postprandial hyperglycemia, which have been linked to both microvascular and macrovascular complications. Moreover, although self-monitoring of blood glucose (SMBG) has been shown to improve glycemic control and quality of life in both insulin-treated and noninsulin-treated diabetes when used within a structured testing regimen $(1-4)[\mathbf{C}, \mathbf{C}, \mathbf{C}, \mathbf{C}]$, it cannot predict impending hypoglycemia or alert for hypoglycemia $(5,6)[\mathbf{C}, \mathbf{C}](7)$.

Real-time continuous glucose monitoring (rtCGM) and intermittently viewed CGM (iCGM) address many of the limitations inherent in $\mathrm{HbA}_{1 \mathrm{c}}$ testing and SMBG. rtCGM uniformly tracks the glucose concentrations in the body's interstitial fluid, providing near real-time glucose data; iCGM uses similar methodology to show continuous glucose measurements retrospectively at the time of checking. Both rtCGM and iCGM facilitate monitoring of time spent in the target glucose range ("time in range"). However, only rtCGM can warn users if glucose is trending toward hypoglycemia or hyperglycemia. With iCGM, these trends can only be viewed after physically scanning the sensor. It is often difficult to distinguish between technologies regarding issues such as calibrations, alarms/alerts, human factors of applying and wearing sensors, and the cost, which are device specific. As these technological details are subject to constant change, the term CGM is used for all issues related to the device class unless indicated otherwise.

In February 2017, the Advanced Technologies \& Treatments for Diabetes (ATTD) Congress convened an international panel of physicians, researchers, and individuals

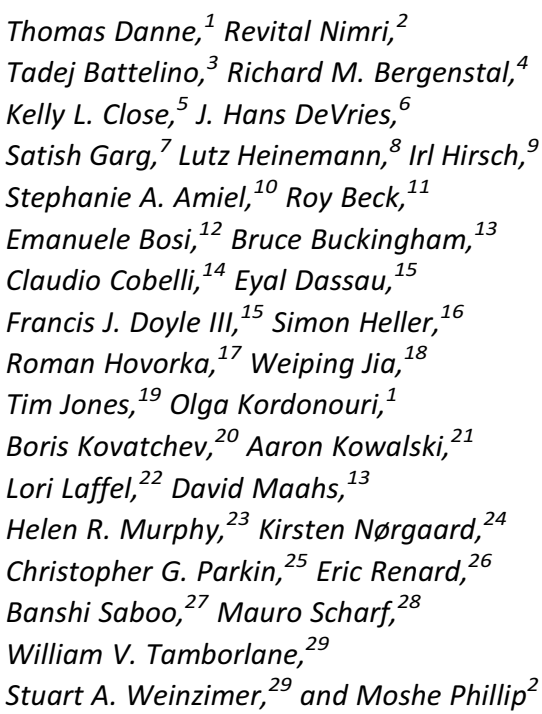

${ }^{1}$ Diabetes Centre for Children and Adolescents, Children's and Youth Hospital "Auf Der Bult," Hannover, Germany

${ }^{2}$ The Myrtle and Henry Hirsch National Center for Childhood Diabetes, The Jesse and Sara Lea Shafer Institute of Endocrinology and Diabetes, Schneider Children's Medical Center of Israel, Petah Tikva, Israel

${ }^{3}$ Department of Pediatric Endocrinology, Diabetes and Metabolic Diseases, University Children's Hospital, Ljubljana University Medical Centre, and Faculty of Medicine, University of Ljubljana, Ljubljana, Slovenia

${ }^{4}$ International Diabetes Center at Park Nicollet, Minneapolis, MN

${ }^{5}$ Close Concerns, San Francisco, $C A$

${ }^{6}$ Academic Medical Center, University of Amsterdam, Amsterdam, the Netherlands

${ }^{7}$ University of Colorado Denver and Barbara Davis Center for Diabetes, Aurora, CO

${ }^{8}$ Science \& Co, Düsseldorf, Germany

${ }^{9}$ Division of Metabolism, Endocrinology, and Nutrition, Department of Medicine, University of Washington School of Medicine, Seattle, WA

${ }^{10}$ Diabetes Research Group, King's College London, London, U.K.

${ }_{11}^{11}$ Jaeb Center for Health Research, Tampa, FL

${ }^{12}$ Diabetes Research Institute, University "Vita-

Salute" San Raffaele, Milan, Italy

${ }^{13}$ Division of Endocrinology and Diabetes, Department of Pediatrics, Stanford University Medical Center, Stanford, CA

${ }^{14}$ Department of Information Engineering, University of Padova, Padova, Italy

${ }^{15}$ John A. Paulson School of Engineering and Applied Sciences, Harvard University, Cambridge, MA ${ }^{16}$ Academic Unit of Diabetes, Endocrinology \& Metabolism, The University of Sheffield, Sheffield, U.K.

${ }^{17}$ Wellcome Trust-MRC Institute of Metabolic Science and Department of Paediatrics, University of Cambridge, Cambridge, U.K. 
with diabetes who are expert in CGM to address these issues. The purpose of the conference was to provide guidance for clinicians, patients, and researchers in utilizing, interpreting, and reporting CGM data in clinical care and research. The panel was divided into subgroups to review the literature and provide evidence-based recommendations for relevant aspects of CGM utilization and reporting. Primary citations were identified for each topic, assigned a level of evidence (7) (indicated next to the corresponding citation in the text), and verified by the expert panel.

This article summarizes the ATTD consensus recommendations and represents the current state of knowledge on CGM results affecting outcomes. The content represents the consensus of the panel members' comprehensive evaluation of the issues. Supporting evidence is included in the online Supplementary Data identified at the end of each section.

\section{LIMITATIONS OF $\mathrm{HbA}_{1 \mathrm{c}}$}

\section{Key Findings}

- The Diabetes Control and Complications Trial (DCCT), followed by the Epidemiology of Diabetes Interventions and Complications (EDIC), demonstrated how elevated $\mathrm{HbA}_{1 \mathrm{c}}$ contributes to complications in type 1 diabetes. The UK Prospective Diabetes Study (UKPDS) confirmed the importance of glycemic control as well as other components of metabolic control, namely blood pressure, on health outcomes in individuals with type 2 diabetes $(8,9)[\mathbf{A}, \mathbf{A}]$.

- Most global organizations recommend target $\mathrm{HbA}_{1 \mathrm{c}}$ levels of $<7.0 \% \quad(53$ $\mathrm{mmol} / \mathrm{mol}$ ) for adults and $<7.5 \%$ (58 $\mathrm{mmol} / \mathrm{mol}$ ) for children, although several organizations suggest an $\mathrm{HbA}_{1 c}$ target of $\leq 6.5 \%$ for adults (10) [E] and children (11) [E]. However, all organizations agree that $\mathrm{HbA}_{1 \mathrm{c}}$ targets should be individualized to each patient.

- Although $\mathrm{HbA}_{1 \mathrm{c}}$ remains the reference marker for assessing glycemic control and predicting the risk of development of long-term complications, it has several limitations: $\mathrm{HbA}_{1 \mathrm{c}} 1$ ) provides only an average of glucose levels over the previous past 2-3 months; 2 ) does not detect hypoglycemia or hyperglycemia on a daily basis; 3 ) is an unreliable measure in patients with anemia (12) [B], hemoglobinopathies (13) [B], or iron deficiency (14) [B] and during pregnancy (15) [B]; 4) does not reflect rapid changes in daily glucose control; and 5) does not provide data as to how to adjust the treatment regimen when $\mathrm{HbA}_{1 \mathrm{c}}$ levels are elevated. In summary, although $\mathrm{HbA}_{1 \mathrm{c}}$ has proved extremely valuable in patient management, is a valuable measure of population health, and remains a validated indicator of glycation as a risk factor for complications, it is not as helpful for personalized diabetes management.

- The literature suggests that ethnic and racial differences exist in glycation rates (16-18) [B,C,C], which affects the accuracy of $\mathrm{HbA}_{1 \mathrm{c}}$ measurements; however, a racial difference was not found in the relationship between mean glucose and fructosamine or glycated albumin levels. This suggests that the racial discordance in glycation rates is specific to red blood cells. The effects of ethnic differences on average $\mathrm{HbA}_{1 \mathrm{c}}$ cannot be entirely explained by measured differences in glycemia, differences in sociodemographic or clinical factors, or differences in access to care or quality of care (19) [E].

- An estimated $\mathrm{HbA}_{1 \mathrm{c}}(\mathrm{eA} 1 \mathrm{C})$ can be calculated if adequate rtCGM/iCGM data (70\% or 10 days of the 14 days of CGM data) are available. The eA1C and laboratory-measured $\mathrm{HbA}_{1 \mathrm{c}}$ may differ to some degree for a given individual because there are many factors that affect an $\mathrm{HbA}_{1 \mathrm{c}}$ reading and tables that convert $\mathrm{HbA}_{1 \mathrm{c}}$ to a mean glucose and vice versa are based on mean values for a population. Knowing how an individual's CGM-derived eA1C compares to their laboratory-measured $\mathrm{HbA}_{1 \mathrm{c}}$ may be helpful for safe and effective clinical management (20) [E].

\section{Recommendations}

- $\mathrm{HbA}_{1 \mathrm{c}}$ should be measured with a device that is certified by the NGSP (National Glycohemoglobin Standardization Program, www.ngsp.org) or the IFCC (International Federation of Clinical Chemistry and Laboratory Medicine, www.ifcchba1c.net).

- Clinicians and patients should target an $\mathrm{HbA}_{1 \mathrm{c}}$ as close to normal as possible without severe hypoglycemia or a significant amount of nonsevere hypoglycemia while at the same time individualizing glycemic targets according to patient age, duration of diabetes, comorbidities, and expected life expectancy, with "lessstrict" $\mathrm{HbA}_{1 \mathrm{c}}$ targets for those more frail (21) $[\mathbf{A}]$.

- When there is a discrepancy between actual $\mathrm{HbA}_{1 \mathrm{c}}$ and the $\mathrm{eA} 1 \mathrm{C}$ based on mean glucose, other glucose measurement methods such as fructosamine, glycated albumin, SMBG, and in particular CGM should be used in conjunction with $\mathrm{HbA}_{1 \mathrm{c}}$ measurements

\footnotetext{
${ }^{18}$ Department of Endocrinology and Metabolism, Shanghai Jiao Tong University Affiliated Sixth People's Hospital, Shanghai Diabetes Institute, Shanghai Key Laboratory of Diabetes Mellitus, Shanghai Clinical Center of Diabetes, Shanghai, China

${ }^{19}$ Telethon Kids Institute and School of Paediatrics and Child Health, The University of Western Australia, and Department of Endocrinology and Diabetes, Princess Margaret Hospital for Children, Perth, Australia

${ }^{20}$ Center for Diabetes Technology, University of Virginia School of Medicine, Charlottesville, VA

${ }^{21}$ JDRF, New York, NY

${ }^{22}$ Pediatric, Adolescent and Young Adult Section and Section on Clinical, Behavioral and Outcomes Research, Joslin Diabetes Center, Harvard Medical School, Boston, MA
}

${ }^{23}$ Norwich Medical School, University of East Anglia, Norwich, U.K.

${ }^{24}$ Department of Endocrinology, Copenhagen University Hospital Hvidovre, Hvidovre, Denmark ${ }^{25}$ CGParkin Communications, Boulder City, NV ${ }^{26}$ Department of Endocrinology, Diabetes, and Nutrition, Montpellier University Hospital, and Institute of Functional Genomics, University of Montpellier, and INSERM Clinical Investigation Centre, Montpellier, France

${ }^{27}$ DiaCare, Ahmedabad, Gujarat, India

${ }^{28}$ Centro de Diabetes Curitiba and Division of Pediatric Endocrinology, Hospital Nossa Senhora das Graças, Curitiba, Brazil

${ }^{29}$ Department of Pediatrics, Yale School of Medicine, New Haven, CT

Corresponding author: Thomas Danne,danne@ hka.de.
This article contains Supplementary Data online at http://care.diabetesjournals.org/lookup/ suppl/doi:10.2337/dc17-1600/-/DC1.

This article is featured in a podcast available at http://www. diabetesjournals.org/content/ diabetes-core-update-podcasts.

(C) 2017 by the American Diabetes Association. Readers may use this article as long as the work is properly cited, the use is educational and not for profit, and the work is not altered. More information is available at http://www. diabetesjournals .org/content/license.

See accompanying articles, pp. 1611, 1614, 1622, 1641, 1644, 1651, and 1661. 
when assessing glycemic control and adjusting therapy.

- CGM data should be used to assess hypoglycemia and glucose variability.

Additional discussion of these recommendations and supporting evidence is presented in Appendix 1 of the Supplementary Data.

\section{USE OF GLUCOSE MONITORING METHODOLOGIES (SMBG AND CGM) TO GUIDE MANAGEMENT AND ASSESS OUTCOMES IN DIFFERENT PATIENT POPULATIONS}

\section{Key Findings}

- SMBG has been shown to be helpful or to correlate with effective management in insulin-treated and noninsulin-treated diabetes $(\mathbf{1 - 4 , 2 2 , 2 3 )}$ [C, C,C,C,A,C]; however, SMBG has notable limitations. First, it requires a fingerstick to obtain a blood sample. Moreover, it only provides a single "point-in-time" measurement, which provides no indication of the direction or rate of change of glucose levels. Thus, using SMBG data alone may result in inappropriate therapy decisions (such as administering correction insulin when blood glucose levels are falling). Second, obtaining glucose data via SMBG is dependent upon the patient's decision to self-monitor. Accordingly, SMBG often fails to detect nocturnal and asymptomatic hypoglycemia $(5,6)[\mathbf{C}, \mathbf{C}]$.

- iCGM provides the current glucose value plus retrospective glucose data for a specified time period upon "scanning." At the time of this writing, only one iCGM system, also known as "flash" monitoring, was available. This system utilizes two components: a glucose sensor, which is inserted the user's upper arm, and a separate touch screen reader device. When the reader device is swiped close to the sensor, the sensor transmits both an instantaneous glucose level and an 8-h trend graph to the reader. The only currently available iCGM device is factory calibrated, lasts up to 14 days, and does not need to be calibrated by the user. However, iCGM lacks alarms for low and high glucose values, and, as with SMBG, measurements are only visualized when the user of the device chooses to make a measurement. Two studies using iCGM have demonstrated significant improvements in hypoglycemia, time in range, glycemic variability, and user satisfaction $(24,25)$ [B,B]. The flash device is also available without the need for scanning in a blinded mode for clinical research or retrospective glucose pattern evaluation.

- rtCGM in unblinded mode provides real-time numerical and graphical information about the current glucose level, glucose trends, and the direction/ rate of change of glucose. Devices with programmable alerts/alarms that warn users of current and/or impending high or low glucose offer additional safety advantages. In Europe, a new type of implantable rtCGM system is available as an alternative for transcutaneous CGM (26) [C].

- Numerous studies have shown that use of rtCGM improves glycemic control and quality of life in both children and adults with type 1 diabetes treated with either continuous subcutaneous insulin infusion or multiple daily insulin injection therapy, improving $\mathrm{HbA}_{1 \mathrm{c}}$, shortening the time spent in hypoglycemia and hyperglycemia, and reducing moderate-to-severe hypoglycemia (27-38) [C,C,B,B,C,C,A,C,B,C,B]. The benefit of rtCGM was seen primarily in those patients who regularly used their devices $(27,29,36)[\mathbf{C}, \mathbf{B}, \mathbf{B}]$. In a lifetime analysis, rtCGM reduced overall diabetesrelated complications (39) [B]. Similar results of the cost-effectiveness of rtCGM versus SMBG were reported using a larger, population-based model (40).

- Using data collected from a metaanalysis of patient-level data (36) [B], sensor-augmented pump therapy was determined to be cost-effective for the treatment of type 1 diabetes in the Swedish health care system (41) [C]. Sensitivity analyses indicated further cost-effectiveness benefit of increasing the amount of rtCGM use from 5 to 7 days a week, and decreasing the use of SMBG was incrementally costeffective at every level.

- Subsequent studies have determined that sensor-augmented pump systems with a low-glucose suspend feature are also cost-effective relative to insulin pump therapy alone, in the Australian (42) [C], U.K. (43) [C], and French (44) [C] health care systems, due to improved glycemic control and reduction in hypoglycemia.

- Benefits of rtCGM use have also been reported in individuals with type 2 diabetes who are managed with or without intensive insulin treatment $(45-47)[B, C, C]$. There are limited data regarding the benefit of rtCGM as an outcome measure for individuals with gestational diabetes mellitus and type 2 diabetes, especially for those who do not use insulin (48) [C].

- The benefit of rtCGM is directly correlated to persistence and frequency of use. A meta-analysis by Pickup et al. (36) [B] found that every 1-day increase of sensor usage per week increased the effect of CGM; the effect on $\mathrm{HbA}_{1 \mathrm{c}}$ is more pronounced the higher the initial $\mathrm{HbA}_{1 \mathrm{c}}$.

\section{Recommendations}

- CGM should be considered in conjunction with $\mathrm{HbA}_{1 \mathrm{c}}$ for glycemic status assessment and therapy adjustment in all patients with type 1 diabetes and patients with type 2 diabetes treated with intensive insulin therapy who are not achieving glucose targets, especially if the patient is experiencing problematic hypoglycemia.

- Structured testing regimens should be defined for patients when SMBG is prescribed.

- All patients should receive training in how to interpret and respond to their glucose data regardless of the monitoring method used. Patient education and training for CGM should utilize standardized programs with follow-up to improve adherence and facilitate appropriate use of data and diabetes therapies.

Additional discussion of these recommendations and supporting evidence is presented in Appendix 2 of the Supplementary Data.

\section{MINIMUM REQUIREMENTS FOR CGM PERFORMANCE}

\section{Key Findings}

- No internationally accepted standard exists for CGM system performance comparable with the International Organization for Standardization (ISO) 15197 standard for SMBG, which specifies design verification procedures and the validation of performance by the intended users. However, ISO/IEEE FDIS $11073-10425$ provides a normative definition of the communication between CGM devices and managers (such as cell phones, personal computers, 
personal health appliances, and set-top boxes) in a manner that enables plugand-play interoperability.

- In contrast to iCGM, the accuracy of current rtCGM systems is dependent on SMBG testing for calibration. Therefore, it is important to have an accurate glucose meter. Successful calibration also requires several conditions; for example, it is best performed when glucose is not changing rapidly. Importantly, users must be educated in the appropriate techniques.

- The mean absolute relative difference (MARD) is currently the most common metric used to assess the performance of CGM systems. MARD is the average of the absolute error between all CGM values and matched reference values. A small percentage indicates that the CGM readings are close to the reference glucose value, whereas a larger MARD percentage indicates greater discrepancies between the CGM and reference glucose values.

- Comparing MARD values from different clinical studies has several limitations, and thus head-to-head studies should be performed. Additional metrics, such as precision absolute relative difference, can be used as well to obtain an additional evaluation of the CGM performance (49) [C].

- Although controversy exists regarding the exact cut point for accuracy, in silico testing has shown that a further lowering of MARD $\leq 10 \%$ from reference values has little additional benefit for insulin dosing (50) [C].

\section{Recommendation}

- Only CGM systems that provide an acceptable level of sensor accuracy should be used.

Additional discussion of this recommendation and supporting evidence is presented is presented in Appendix 3 of the Supplementary Data.

\section{DEFINITION AND ASSESSMENT OF HYPOGLYCEMIA IN CLINICAL STUDIES}

\section{Key Findings}

- Hypoglycemia remains a major barrier for glycemic control and a common complication of diabetes treatment, especially in type 1 diabetes (51) [E]

- In adults with type 1 diabetes, severe hypoglycemia is more related to duration of diabetes and socioeconomic status than $\mathrm{HbA}_{1 \mathrm{c}}$ (35) [C]. Similarly, in children aged 6-17 years old with type 1 diabetes (52) [C] or adults with type 2 diabetes (mostly receiving insulin or sulfonylureas [53] [B]), severe hypoglycemia was most common among those with the lowest and highest $\mathrm{HbA}_{1 \mathrm{c}}$ levels.

- Needing assistance is the usual concise definition for severe hypoglycemia. Most children require assistance with all hypoglycemia, not just severe hypoglycemia (54) [C]. Therefore, severe hypoglycemia in children is often defined as an event associated with a seizure or loss of consciousness or requiring emergency medical personnel, a visit to the emergency department, or a hospital admission. In adults, the definition of severe hypoglycemia often includes episodes associated with coma or seizure, for which the patient, perhaps being on their own, recovered spontaneously.

- The degree of hypoglycemia that causes clinical symptoms and counterregulatory response is specific to the individual and depends on the personal level of glycemic control (54) [C].

- Studies indicate that hypoglycemia for two or more hours impairs hormonal responses $(55,56)[\mathbf{C}, \mathbf{B}]$.

- Gradation of hypoglycemic events may be valuable: specifically, that of a prolonged hypoglycemic event, in which the CGM levels indicate glucose levels $<54 \mathrm{mg} / \mathrm{dL}$ (3.0 mmol/L) for $\geq 120 \mathrm{~min}$. While this metric is somewhat arbitrary, a study by Öz et al. (57) [B] found that the glycogen signal decreases with a rate of $\sim 10 \%$ per hour in the human brain at blood glucose levels of $<54 \mathrm{mg} / \mathrm{dL}(3.0 \mathrm{mmol} / \mathrm{L})$ indicating a mobilization rate commensurate with the severity of hypoglycemia.

- The low blood glucose index (LBGI) is a metric specifically designed to calculate the risk for hypoglycemia as reflected by SMBG data (58) [B] However, LBGI calculations based on CGM data tend to slightly underestimate risk, particularly in the low-risk range (59) [C].

\section{Recommendations}

- The definition of hypoglycemia should take into consideration several parameters: the compartment of measurement (arterial, venous, and capillary blood or interstitial), the nadir level of blood glucose measured, and the duration of the event and related symptoms.

- When assessing hypoglycemia using CGM, the accuracy of the data in the lower glycemic range should be considered.

- The following classifications of hypoglycemia, based on clinical evaluation, should be used in categorizing levels of hypoglycemia.

- Level 1: a hypoglycemia alert glucose value of $<70-54 \mathrm{mg} / \mathrm{dL}$ (3.9-3.0 $\mathrm{mmol} / \mathrm{L}$ ) with or without symptoms. This should be considered an alert that the individual may be at risk for developing hypoglycemia and should work to minimize the time spent in this range to reduce the risk of developing more clinically significant hypoglycemia. This need not be reported routinely in clinical studies, although that would depend on the purpose of the study. Nevertheless, most clinicians want to know how often patients are $<70-54 \mathrm{mg} / \mathrm{dL}(3.9-3.0 \mathrm{mmol} / \mathrm{L})$ and would act to reduce the time spent in this range to minimize the risk of more clinically significant hypoglycemia occurring.

- Level 2: a glucose level of $<54 \mathrm{mg} / \mathrm{dL}$ (3.0 $\mathrm{mmol} / \mathrm{L})$ with our without symptoms. This should be considered clinically significant hypoglycemia requiring immediate attention.

- Level 3: severe hypoglycemia. This denotes cognitive impairment requiring external assistance for recovery (7) [E] but is not defined by a specific glucose value.

- For clinical study CGM outcomes reports, hypoglycemia values $<54 \mathrm{mg} / \mathrm{dL}$ (3.0 $\mathrm{mmol} / \mathrm{L}$ ) should be given more weight or importance than those $<70-54 \mathrm{mg} / \mathrm{dL}$ (3.9-3.0 mmol/L).

- When assessing hypoglycemia in clinical care, other important consequences or adverse patient-reported outcomes should be considered.

- Reduced awareness of subsequent hypoglycemia.

- Associated cardiac arrhythmia, confusion, or abnormal or combative behavior.

- Weight gain.

- Fear of hypoglycemia.

- Hypoglycemia should be quantified in the following ways.

- As the percentage of CGM values that are below a given threshold $(<70$ $\mathrm{mg} / \mathrm{dL}$ [3.9 $\mathrm{mmol} / \mathrm{L}]$ or $<54 \mathrm{mg} / \mathrm{dL}$ 
[3.0 $\mathrm{mmol} / \mathrm{L}]$ ) or the number of minutes or hours below these thresholds.

- As the number of hypoglycemic events that occur over the given CGM reporting period.

- A hypoglycemic event should be defined as follows.

- Beginning of a CGM event: readings below the threshold for at least $15 \mathrm{~min}$ is considered an event. For example, at least $15 \mathrm{~min}<54 \mathrm{mg} / \mathrm{dL}$ (3.0 $\mathrm{mmol} / \mathrm{L}$ ) to define a clinically significant (level 2) hypoglycemic event.

- End of a CGM event: readings for 15 $\mathrm{min}$ at $\geq 70 \mathrm{mg} / \mathrm{dL}$ (3.9 mmol/L).

- A second hypoglycemic event outcome of prolonged hypoglycemia is considered when CGM levels are $<54 \mathrm{mg} / \mathrm{dL}$ (3.0 mmol/L) for consecutive $120 \mathrm{~min}$ or more.

- LBGI should be reviewed when assessing hypoglycemia risk.

Additional discussion of these recommendations and supporting evidence is presented in Appendix 4 of the Supplementary Data.

\section{ASSESSMENT OF GLYCEMIC VARIABILITY}

Key Findings

- Numerous studies have focused on glycemic variability as an independent risk factor for diabetes complications, particularly cardiovascular disease (60-63) [C,E,C,C], and on the effects of glycemic variability on cognitive function and quality of life (64) [C].

- Acceptance of glycemic variability as a clinically valuable marker of glycemic control has greatly expanded the understanding of glycemic control beyond $\mathrm{HbA}_{1 \mathrm{c}}$ alone (65-68) [E,E,E,E].

- The interpretation of average blood glucose is relatively straightforward, providing a direct relationship to $\mathrm{HbA}_{1 \mathrm{c}}$. However, because glycemic variability is a reflection of a dynamic process, understanding and measuring it is more complex $(69,70)$ [E,C]. Beyond the setting of laboratory experiments, the data sources available for routine estimation of glycemic variability include episodic SMBG records and CGM traces (71) [B]. The density of the available data determines what properties of glycemic variability can be investigated.
- Glycemic variability is a process characterized by the amplitude, frequency, and duration of the fluctuation.

- Both the amplitude and the timing of blood glucose fluctuations contribute to the risks for hypoglycemia and hyperglycemia associated with diabetes (72) [C]. Increased glucose variability is consistently associated with mortality in the intensive care unit $(73,74)$ $[\mathbf{C}, \mathbf{B}]$ and is a consistent predictor of hypoglycemia, both in prospective studies and within the setting of randomized clinical trials $(64,75)$ [C,B].

- When quantifying glucose variability from CGM data, the following physiological and statistical factors should be considered.

- In healthy individuals, the metabolic system has a physiological equilibrium range (e.g., fasting blood glucose) to which it returns if left undisturbed; with the progression of diabetes, this equilibrium range moves up.

- This physiological equilibrium range is relatively universal (hence the diagnostic criteria for prediabetes and diabetes). Therefore, the objective of diabetes control is to keep blood glucose levels in the vicinity of a commonly accepted range (not the mean for a person, which is individual).

- Deviations from the range in both directions carry risks. These risks increase with the amplitude of the deviations, nonlinearly and asymmetrically, into the hypoglycemic and hyperglycemic ranges.

o The timing of the deviations is of essence as it reflects system (person) dynamics and system stability. However, most of the traditional glycemic variability metrics ignore the time axis of CGM data.

- Mathematical methods (e.g., risk analysis, time series) are well developed and can be adapted to diabetes, keeping in mind the objectives of diabetes control.

- CGM data reflect the dynamics of glucose fluctuations by including all of these dimensions. A recent analysis of CGM data in comparison with blood glucose data obtained in a large study with patients with type 1 diabetes showed how glycemic variability indices are related and demonstrated the impact of CGM use on glycemic variability (76) [C].
- SD, coefficient of variation (CV), and mean amplitude of glucose excursions are widely used to quantify glycemic variability. The CV (which is the SD divided by the mean) has the advantage of being a metric relative to the mean, which makes it more descriptive of hypoglycemic excursions than the SD alone. For example, a population with a mean glucose of $150 \mathrm{mg} / \mathrm{dL}$ and an SD of 60 would have a CV of $40 \%$.

- Stable glucose levels are defined as a $\mathrm{CV}<36 \%$, and unstable glucose levels are defined as $C V \geq 36 \%$ (77) [E].

\section{Recommendations}

- Glycemic variability evaluated from CGM data should be considered among other factors of the overall clinical representation of glycemic control.

- CV should be considered the primary measure of variability; however, many clinicians may want to see SD reported as a key secondary glycemic variability measure since it is a metric with which they are familiar.

- The recommended metrics for glycemic variability should be included in summary statistics for data downloaded from CGM devices into reports.

Additional discussion of these recommendations and supporting evidence is presented in Appendix 5 of the Supplementary Data.

\section{TIME IN "RANGES"}

- Time in range (TIR) generally refers to the time spent in an individual's target glucose range (usually $70-180 \mathrm{mg} / \mathrm{dL}$ [3.9-10 mmol/L] but occasionally 70$140 \mathrm{mg} / \mathrm{dL}$ [3.9-7.8 mmol/L]). TIR measurements add valuable information to assess the level of current glycemic control in addition to what is known from the $\mathrm{HbA}_{1 \mathrm{c}}$. However, clinicians, researchers, and regulators now know that time in target range alone is not an adequate description of overall glycemic control. It is also necessary to quantitate the times below and above target range, using a few severity thresholds for each level (78) [E]. Thus, time in "ranges" (TIRs) provides a more illustrative metric for clinical and research purposes.

- TIRs are useful for a research comparison of interventions and can help patients understand whether the amount 
of clinically significant hypoglycemia or hyperglycemia they are experiencing is improving over time. Breaking out the time in hypoglycemia and hyperglycemia into level 1 (monitor and take action if needed) and level 2 (immediate action required due to the more potentially clinically significant nature of the glucose levels) can guide the urgency and degree of clinical response.

\section{Composite Measures}

- Because the function of CGM use is to monitor glucose levels with the ultimate goal of improving glycemic control, it makes clinical sense to combine TIRs data with other measures.

- $\mathrm{HbA}_{1 \mathrm{c}}$ level and time in level 2 (clinically significant/immediate action required) hypoglycemia is one such combined measure.

- Time in target range combined with time in level 2 hypoglycemia is another such combined measure. This combined set of measures could be set up as a coprimary outcome for a clinical trial asking whether one therapy is more effective than another in achieving an increased time in target range (70-180 $\mathrm{mg} / \mathrm{dL}$ ) while also being noninferior for the level 2 hypoglycemia achieved. One then needs to further define the parameters of judging noninferior status. These examples make clinical sense, since one wants to improve glucose control ( $\mathrm{HbA}_{1 \mathrm{c}}$ or TIR) while also reducing or at least not increasing hypoglycemia.

- Even broader combined measures of diabetes management such as targets for desired diabetes management are being explored (e.g., $\mathrm{HbA}_{1 \mathrm{c}}+$ hypoglycemia + weight gain or $\mathrm{HbA}_{1 \mathrm{c}}+$ blood pressure + $\mathrm{LDL}$ or $\mathrm{HbA}_{1 \mathrm{c}}+$ blood pressure + LDL + aspirin use if high-risk cardiovascular disease + no tobacco use). These composites emphasize the importance of taking a multifactorial approach to reducing diabetes complications, particularly cardiovascular disease.

\section{Recommendations}

- Percentages of time in ranges (target, hypoglycemia, and hyperglycemia) should be assessed and reported.

- Different TIRs in conjunction with a measure of glycemic variability should be reported as key diabetes control metrics in clinical studies.

Additional discussion of these recommendations and supporting evidence is presented in Appendix 6 of the Supplementary Data.

Table 1-Key metrics for CGM data analysis and reporting

\begin{tabular}{|c|c|c|}
\hline CGM metric & Measures & ATTD consensus \\
\hline 1 & $\begin{array}{l}\text { Mean glucose } \\
\text { Severe hypoglycemia* } \\
\text { Percentage of time in hypoglycemic ranges, } \mathrm{mg} / \mathrm{dL} \text { ( } \mathrm{mmol} / \mathrm{L} \text { ) }\end{array}$ & $\begin{array}{l}\sqrt{ } \text { (calculated) } \\
\text { Clinical diagnosis: event requiring assistance (level 3) }\end{array}$ \\
\hline 2 & Clinically significant/very low/immediate action required & $<54(<3.0)$ (level 2) \\
\hline 3 & $\begin{array}{l}\text { Alert/low/monitor } \\
\text { Percentage of time in target range, } \mathrm{mg} / \mathrm{dL} \text { ( } \mathrm{mmol} / \mathrm{L} \text { ) }\end{array}$ & $<70-54$ (<3.9-3.0) (level 1) \\
\hline 4 & $\begin{array}{l}\text { Default } \\
\text { Secondary } \\
\text { Percentage of time in hyperglycemic ranges, } \mathrm{mg} / \mathrm{dL} \text { ( } \mathrm{mmol} / \mathrm{L} \text { ) }\end{array}$ & $\begin{array}{l}70-180(3.9-10.0) \\
70-140(3.9-7.8)\end{array}$ \\
\hline 5 & Alert/elevated/monitor & $>180(>10)($ level 1$)$ \\
\hline \multirow[t]{3}{*}{6} & $\begin{array}{l}\text { Clinically significant/very elevated/immediate action } \\
\text { required }\end{array}$ & $>250$ (>13.9) (level 2) \\
\hline & Diabetic ketoacidosis* & $\begin{array}{l}\text { Clinical diagnosis: ketones, acidosis, and usually hyperglycemia } \\
\text { (level 3) }\end{array}$ \\
\hline & Glycemic variability & \\
\hline 7 & $\begin{array}{l}\text { Primary glycemic variability } \\
\text { Stable } \\
\text { Unstable }\end{array}$ & $\begin{array}{l}\text { CV } \\
C V<36 \% \\
C V \geq 36 \%\end{array}$ \\
\hline & Secondary glycemic variability & SD \\
\hline 8 & eA1C & $\sqrt{ }$ (calculated) \\
\hline \multirow[t]{2}{*}{9} & Three time blocks: sleep, wake, $24 \mathrm{~h}$ & 12:00 A.M.-6:00 A.M., $6: 00$ A.M.-12:00 A.M., 12 A.M.-12:00 A.M. \\
\hline & Recommended data sufficiency & \\
\hline 10 & Collection period (minimum no. of weeks) & 2 \\
\hline 11 & $\begin{array}{l}\text { Percentage of expected CGM readings (minimum } \\
\text { percentage) }\end{array}$ & $70-80$ (10 of 14 days) \\
\hline 12 & $\begin{array}{l}\text { Episodes of hypoglycemia/hyperglycemia (minimum no. of } \\
\text { minutes) (with beginning and end of episode } \\
\text { defined) }\end{array}$ & $15 \mathrm{~min}$ \\
\hline 13 & Area under the curve & $\sqrt{ }$ (calculated) \\
\hline 14 & Risk of hypoglycemia and hyperglycemia & LBGI/HBGI recommended \\
\hline 15 & Standardized CGM visualization of data & AGP recommended \\
\hline
\end{tabular}

* Severe hypoglycemia (level 3) and diabetic ketoacidosis (level 3) are not key CGM metrics per se. However, these conditions are included in the table because they are important clinical categories that must be assessed and documented. 


\section{VISUALIZATION, ANALYSIS, AND DOCUMENTATION OF KEY CGM METRICS}

\section{Key Findings}

- Standardizing glucose reporting and analysis similar to electrocardiogram output is vital to optimizing clinical decision-making in diabetes. Further optimizing of such tools and expanding them into shared decision-making guides is needed.

- Reporting CGM data in a standardized way, in conjunction with an $\mathrm{HbA}_{1 \mathrm{c}}$ value and other clinical conditions (e.g., severe hypoglycemia, diabetic ketoacidosis) would foster a precise definition of this composite goal. Using a standardized composite goal, the medical community could establish with more confidence whether a particular insulin formulation, new technology for insulin delivery, or an innovative patientcentered approach to care was an important factor in helping individuals with diabetes reach optimal glycemic control.

- Standardized tools such as the Ambulatory Glucose Profile (AGP [79]), Pattern Snapshot (Medtronic) (80), Clarity (Dexcom) (81), and others from various device makers and data management companies are now available. Use of the AGP approach was previously endorsed by an expert panel of clinicians in a consensus conference held in 2012 (82) [E] and is recommended by this consensus group as a standard for visualization of CGM data.

- Integration of standardized metrics into electronic health records is important to maximize the clinical workflow and facilitate remote communications with patients.

- Patient responses to the current glucose level, trend arrows indicating rate of change of glucose, and qualitative analysis of a graphical display of glucose versus time do not require stability of patterns. However, retrospective analysis of CGM is dependent on stability of patterns from day to day (83) [B].

- A minimum of 14 consecutive days of data with approximately $70 \%$ of possible CGM readings over those 14 days appears to generate a report that enables optimal analysis and decision-making; standard reporting and visualization of CGM data are important.

\section{Recommendations}

- Fourteen key metrics should be utilized to assess glycemic control and documented.

1. Mean glucose.

2. Percentage of time in level 2 hypoglycemic range $(<54 \mathrm{mg} / \mathrm{dL}[3.0 \mathrm{mmol} / \mathrm{L}])$. Urgency for action: clinically significant/ very low/immediate action required.

3. Percentage of time in level 1 hypoglycemic range $(<70-54 \mathrm{mg} / \mathrm{dL}$ [3.9$3.0 \mathrm{mmol} / \mathrm{L}])$. Urgency for action: alert/ low/monitor.

4. Percentage of time in target range: 70 $180 \mathrm{mg} / \mathrm{dL}$ (3.9-10.0 mmol/L) (default); 70-140 mg/dL (3.9-7.8 mmol/L) (secondary); individual targets closer to the physiological range can be defined, depending on age, comorbidities, and/ or patient adherence.

5. Percentage of time in level 1 hyperglycemic range ( $>180 \mathrm{mg} / \mathrm{dL}[10.0$ $\mathrm{mmol} / \mathrm{L}])$. Urgency for action: alert/ elevated/monitor.

6. Percentage of time in level 2 hyperglycemic range ( $>250 \mathrm{mg} / \mathrm{dL}$ [13.9 mmol/L]). Urgency for action: clinically significant/ very elevated/immediate action.
7. Glycemic variability, reported as CV (primary) and SD (secondary).

8. eA1C.

9. Data for glucose metrics $(1-6,8)[\mathbf{C}, \mathbf{C}, \mathbf{C}$, $\mathbf{C}, \mathbf{C}, \mathbf{C}, \mathbf{A}]$ reported in three time blocks (sleep, wake, $24 \mathrm{~h}$ ) with the default times for the sleep (12:00 A.M.-6:00 A.M.) and wake (6:00 A.M.-12:00 A.M.) often written as midnight to 6:00 A.M. and 6:00 A.M. to midnight, respectively.

10. Data sufficiency: minimum 2 weeks of data.

11. Data sufficiency: $70-80 \%$ of possible CGM readings over a 2-week period.

12. Episodes of hypoglycemia and hyperglycemia, using a standard definition of episodes.

13. Area under the curve (recommended for research purposes). This can be calculated from CGM analysis software and is recommended for research purposes, as it is a measure that integrates to some extent the severity of a high or low glucose along with the duration of the abnormality.

14. Risk of hypoglycemia and hyperglycemia (LBGI and high blood glucose index [HBGI] recommended).
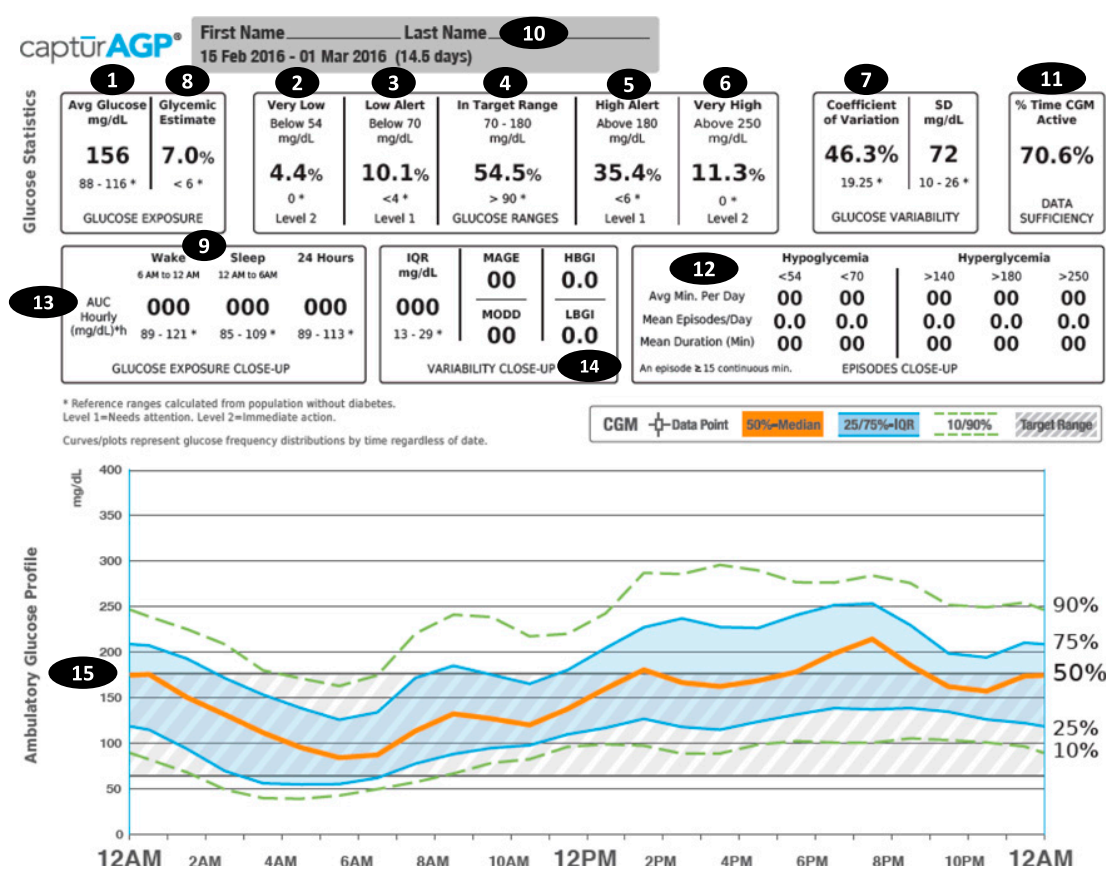

Figure 1-The electronic AGP report visualizes the key CGM metrics: 1) mean glucose, 2) hypoglycemia: clinically significant/very low/immediate action required, 3) hypoglycemia: alert/low/ monitor, 4) target range, 5) hyperglycemia: alert/elevated/monitor, 6) hyperglycemia: clinically significant/very elevated/immediate action required, 7) glycemic variability, 8) eA1C, 9) time blocks, 10) collection period, 11) percentage of expected readings, 12) hypoglycemia/hyperglycemia episodes, 13) area under the curve, 14) hypoglycemia/hyperglycemia risk, and 15) standardized rtCGM/ iCGM visualization. AUC, area under the curve; Avg; average; IQR, interquartile range; MAGE, mean amplitude of glucose excursions; MODD, mean of daily differences. 
- Standardized software for visualization and reporting of the 14 key CGM metrics should be considered an additional component (no. 15) of analysis and documentation (use of the AGP is recommended).

- Although severe hypoglycemia (level 3 hypoglycemia) and diabetic ketoacidosis (level 3 hyperglycemia) are not CGM data-based determinations, they should be reported and documented.

- For research purposes, median and interquartile range should be presented for all measurements.

- Conduct further studies in a variety of patient groups (including the pediatric population, pregnant individuals, those with renal insufficiency, and the elderly) to determine acceptable and achievable time in range and the accompanying acceptable rates of hypoglycemia.

The key metrics for CGM analysis and reporting are presented in Table 1. Figure 1 illustrates how these metrics are presented in the AGP.

\section{CONCLUSIONS}

CGM is a robust research tool, and continuous glucose data should be recognized by governing bodies as a valuable and meaningful end point to be used in clinical trials of new drugs and devices for diabetes treatment. The identification of hypoglycemia is as important as the measurement of time in range in clinical trials. Quantifying the duration and magnitude of glycemic excursions provides another means of assessing glucose control. The unifying theme of trials investigating the usefulness of CGM technologies is that the device must be worn on a near-daily basis to optimize its benefits.

The expert panel concludes that, in clinical practice, the advanced metrics of assessing continuous glucose data presented here are appropriate as outcome parameters that complement $\mathrm{HbA}_{1 \mathrm{c}}$ for a wide range of patients with diabetes and should be considered for use to help them improve glycemic control provided that appropriate educational and technical support is available.

Acknowledgments. The consensus group participants wish to thank ATTD for organizing and coordinating the meeting. They also wish to thank Rachel Naveh (National Center for Child- hood Diabetes, The Jesse and Sara Lea Shafer Institute of Endocrinology and Diabetes, Schneider Children's Medical Center of Israel) for assistance in organizing the meeting and the diaTribe Foundation (Ava Runge and Jim Hirsch) for editorial support.

Funding. Support for the CGM consensus conference and development of this article was provided by the ATTD Congress. Abbott Laboratories, Dexcom, Insulet Corporation, Eli Lilly, Medtronic, Roche Diabetes Care, and Sanofi provided funding to ATTD to support the consensus meeting. Editorial support was provided by C.G.P. (CGParkin Communications) through a grant from the diaTribe Foundation.

Duality of Interest. T.D. has received speaker honoraria and research support and has consulted for Abbott, Bayer, Bristol-Myers Squibb, AstraZeneca, Boehringer Ingelheim, Dexcom, Eli Lilly, Medtronic, Novo Nordisk, Sanofi, and Roche. T.D. is a shareholder of DreaMed. T.B. served on advisory boards of Novo Nordisk, Sanofi, Eli Lilly, Boehringer Ingelheim, Medtronic, and Bayer HealthCare. T.B.'s institution received research grant support, with receipt of travel and accommodation expenses in some cases, from Abbott, Medtronic, Novo Nordisk, GluSense, Sanofi, Sandoz, and Diamyd. T.B. received honoraria for participating on the speakers' bureaus of Eli Lilly, Bayer, Novo Nordisk, Medtronic, Sanofi, and Roche. T.B. owns stocks of DreaMed. R.M.B. has received research support from and acted as a consultant or has been on a scientific advisory board for Abbott Diabetes Care, Becton Dickinson, Dexcom, Eli Lilly, Glooko, The Leona M. and Harry B. Helmsley Charitable Trust, Hygieia, Johnson \& Johnson, Medtronic, Merck, Novo Nordisk, Roche, and Sanofi. R.M.B.'s employer, the nonprofit Health Partners Institute, contracts for his services, and no personal income goes to R.M.B. R.M.B. has inherited Merck stock. R.M.B. is a volunteer for the American Diabetes Association and JDRF and has worked on the development and implementation of the AGP. J.H.D. has received speaker honoraria and research support from and has consulted for Abbott, Dexcom, Medtronic, Merck Sharp \& Dohme, Novo Nordisk, Sanofi, Roche, Senseonics, and Zealand. R.B. declared no personal financial arrangements with any company. R.B.'s employer, the Jaeb Center for Health Research, has received grant support from Dexcom, Animas, Bigfoot Biomedical, and Tandem; nonfinancial study support from Dexcom, Abbott, and Roche; and consulting fees from Eli Lilly and Insulet. E.D. has served on advisory panels or has been a consultant for Animas, Insulet, and Eli Lilly and has received research support from Dexcom, Insulet, Animas, and Xeris. R.H. has received speaker honoraria from Eli Lilly, Novo Nordisk, and AstraZeneca; served on advisory panels for Eli Lilly and Novo Nordisk; and received license fees from B. Braun and Medtronic. H.R.M. sits on the Medtronic European Scientific Advisory Board. E.R. has received consultancy honoraria from A. Menarini Diagnostics, Abbott, Becton Dickinson, Cellnovo, Dexcom, Eli Lilly, Insulet, Johnson \& Johnson, Medtronic, Novo Nordisk, Roche, and Sanofi and research support from Abbott, Dexcom, Insulet, and Roche. W.V.T. has received consulting fees from Eli Lilly, Novo Nordisk, Sanofi, and Medtronic. S.A.W. served as a consultant for Insulet. M.P. is on the advisory panels of Sanofi, Medtronic, Novo Nordisk, and Eli Lilly. The institute that M.P. heads has received research support from Medtronic, Novo Nordisk, Eli Lilly, Merck, Sanofi, Bristol-Myers Squibb, Kamada, and Lexicon. M.P. received honoraria for participating on the speakers bureaus of Eli Lilly and Abbott and is the chairman and chief science officer and a shareholder at DreaMed Diabetes, Ltd. No other potential conflicts of interest relevant to this article were reported.

\section{References}

1. Kato N, Cui J, Kato M. Structured self-monitoring of blood glucose reduces glycated hemoglobin in insulin-treated diabetes. J Diabetes Investig 2013; 4:450-453

2. Polonsky WH, Fisher L, Schikman $\mathrm{CH}$, et al. Structured self-monitoring of blood glucose significantly reduces $\mathrm{A} 1 \mathrm{C}$ levels in poorly controlled, noninsulin-treated type 2 diabetes: results from the Structured Testing Program study. Diabetes Care 2011;34:262-26

3. Franciosi M, Lucisano G, Pellegrini F, et al.; ROSES Study Group. ROSES: role of self-monitoring of blood glucose and intensive education in patients with type 2 diabetes not receiving insulin. A pilot randomized clinical trial. Diabet Med 2011;28:789-796

4. Kempf K, Kruse J, Martin S. ROSSO-in-praxi follow-up: long-term effects of self-monitoring of blood glucose on weight, hemoglobin A1c, and quality of life in patients with type 2 diabetes mellitus. Diabetes Technol Ther 2012;14:59-64

5. Bolli GB. Hypoglycaemia unawareness. Diabetes Metab 1997;23(Suppl. 3):29-35

6. Gold AE, MacLeod KM, Frier BM. Frequency of severe hypoglycemia in patients with type I diabetes with impaired awareness of hypoglycemia. Diabetes Care 1994;17:697-703

7. American Diabetes Association. Standards of Medical Care in Diabetes-2017. Diabetes Care 2017;40(Suppl. 1):S1-S135

8. Orchard TJ, Nathan DM, Zinman B, et al.; Writing Group for the DCCT/EDIC Research Group. Association between 7 years of intensive treatment of type 1 diabetes and long-term mortality. JAMA 2015;313:45-53

9. Holman RR, Paul SK, Bethel MA, Matthews DR, Neil HAW. 10-year follow-up of intensive glucose control in type 2 diabetes. N Engl J Med 2008;359: 1577-1589

10. Garber AJ, Abrahamson MJ, Barzilay JI, et al.; American Association of Clinical Endocrinologists (AACE); American College of Endocrinology (ACE). Consensus statement by the American Association of Clinical Endocrinologists and American College of Endocrinology on the comprehensive type 2 diabetes management algorithm - 2016 Executive Summary. Endocr Pract 2016;22:84-113 11. National Institute for Health and Care Excellence (NICE). Diabetes (type 1 and type 2) in children and young people: diagnosis and management, 2015. NICE guideline [NG18]. London, U.K., National Institute for Health and Care Excellence. Available from www.nice.org.uk/guidance/ NG18. Accessed 4 May 2017

12. National Institute of Diabetes and Digestive and Kidney Diseases. Sickle cell trait \& other hemoglobinopathies \& diabetes (for providers) [Internet], 2014. Available from http://diabetes .niddk.nih.gov/dm/pubs/hemovari-A1C/index .aspx. Accessed 26 August 2017

13. Bry L, Chen PC, Sacks DB. Effects of hemoglobin variants and chemically modified derivatives 
on assays for glycohemoglobin. Clin Chem 2001; 47:153-163

14. Ford ES, Cowie CC, Li C, Handelsman Y, Bloomgarden ZT. Iron-deficiency anemia, noniron-deficiency anemia and $\mathrm{HbA1C}$ among adults in the US. J Diabetes 2011;3:67-73

15. Nielsen LR, Ekbom P, Damm $\mathrm{P}$, et al. $\mathrm{HbA}_{1 \mathrm{c}}$ levels are significantly lower in early and late pregnancy. Diabetes Care 2004;27:1200-1201

16. Bergenstal RM, Gal RL, Connor CG, et al.; T1D Exchange Racial Differences Study Group. Racial differences in the relationship of glucose concentrations and hemoglobin A1c levels. Ann Intern Med 2017;167:95-102

17. Shipman KE, Jawad M, Sullivan KM, Ford C, Gama R. Ethnic/racial determinants of glycemic markers in a UK sample. Acta Diabetol 2015;52: 687-692

18. Wolffenbuttel BHR, Herman WH, Gross JL, Dharmalingam M, Jiang $\mathrm{HH}$, Hardin DS. Ethnic differences in glycemic markers in patients with type 2 diabetes. Diabetes Care 2013;36:2931-2936

19. Herman WH. Are there clinical implications of racial differences in $\mathrm{HbA}_{1 \mathrm{c}}$ ? Yes, to not consider can do great harm! Diabetes Care 2016;39:1458-1461 20. Beck RW, Connor CG, Mullen DM, Wesley, DM, Bergenstal RM. The fallacy of average: how using $\mathrm{HbA} 1 \mathrm{c}$ alone to assess glycemic control can be misleading. Diabetes Care 2017;40:994-999 21. Fullerton B, Jeitler $K$, Seitz $M$, Horvath $K$, Berghold A, Siebenhofer A. Intensive glucose control versus conventional glucose control for type 1 diabetes mellitus. Cochrane Database Syst Rev 2014;14:CD009122

22. Nathan DM, Genuth S, Lachin J, et al.; Diabetes Control and Complications Trial Research Group. The effect of intensive treatment of diabetes on the development and progression of long-term complications in insulin-dependent diabetes mellitus. N Engl J Med 1993;329:977-986 23. Miller KM, Beck RW, Bergenstal RM, et al.; T1D Exchange Clinic Network. Evidence of a strong association between frequency of selfmonitoring of blood glucose and hemoglobin $A_{1 c}$ levels in T1D Exchange clinic registry participants. Diabetes Care 2013;36:2009-2014

24. Bolinder J, Antuna R, Geelhoed-Duijvestijn P, Kröger J, Weitgasser R. Novel glucose-sensing technology and hypoglycaemia in type 1 diabetes: a multicentre, non-masked, randomised controlled trial. Lancet 2016;388:2254-2263

25. Haak T, Hanaire H, Ajjan R, Hermanns N, Riveline JP, Rayman G. Flash glucose-sensing technology as a replacement for blood glucose monitoring for the management of insulin-treated type 2 diabetes: a multicenter, open-label randomized controlled trial. Diabetes Ther 2016;8:55-73

26. Kropff J, Choudhary P, Neupane S, et al. Accuracy and longevity of an implantable continuous glucose sensor in the PRECISE study: a 180-day, prospective, multicenter, pivotal trial. Diabetes Care 2017;40:63-68

27. Juvenile Diabetes Research Foundation Continuous Glucose Monitoring Study Group. Effectiveness of continuous glucose monitoring in a clinical care environment: evidence from the Juvenile Diabetes Research Foundation Continuous Glucose Monitoring (JDRF-CGM) trial. Diabetes Care 2010; 33:17-22

28. Hermanides J, Nørgaard K, Bruttomesso D, et al. Sensor-augmented pump therapy lowers $\mathrm{HbA}_{1 \mathrm{c}}$ in suboptimally controlled type 1 diabetes; a randomized controlled trial. Diabet Med 2011; 28:1158-1167

29. Battelino T, Conget I, Olsen B, et al.; SWITCH Study Group. The use and efficacy of continuous glucose monitoring in type 1 diabetes treated with insulin pump therapy: a randomised controlled trial. Diabetologia 2012;55:3155-3162 30. New JP, Ajjan R, Pfeiffer AF, Freckmann G Continuous glucose monitoring in people with diabetes: the randomized controlled Glucose Leve Awareness in Diabetes Study (GLADIS). Diabet Med 2015;32:609-617

31. Wong JC, Foster NC, Maahs DM, et al.; T1D Exchange Clinic Network. Real-time continuous glucose monitoring among participants in the T1D Exchange clinic registry. Diabetes Care 2014;37:2702-2709

32. Riveline JP, Schaepelynck P, Chaillous L, et al. EVADIAC Sensor Study Group. Assessment of patient-led or physician-driven continuous glucose monitoring in patients with poorly controlled type 1 diabetes using basal-bolus insulin regimens: a 1-year multicenter study. Diabetes Care 2012;35:965-971

33. Rachmiel M, Landau Z, Boaz M, et al. The use of continuous glucose monitoring systems in a pediatric population with type 1 diabetes mellitus in real-life settings: the AWeSoMe Study Group experience. Acta Diabetol 2015;52:323-329

34. Bergenstal RM, Klonoff DC, Garg SK, et al.; ASPIRE In-Home Study Group. Threshold-based insulin-pump interruption for reduction of hypoglycemia. N Engl J Med 2013;369:224-232

35. Weinstock RS, Xing D, Maahs DM, et al.; T1D Exchange Clinic Network. Severe hypoglycemia and diabetic ketoacidosis in adults with type 1 diabetes: results from the T1D Exchange clinic registry. J Clin Endocrinol Metab 2013;98:3411-3419

36. Pickup JC, Freeman SC, Sutton AJ. Glycaemic control in type 1 diabetes during real time continuous glucose monitoring compared with self monitoring of blood glucose: meta-analysis of randomised controlled trials using individual patient data. BMJ 2011;343:d3805

37. Garg SK, Voelmle MK, Beatson CR, et al. Use of continuous glucose monitoring in subjects with type 1 diabetes on multiple daily injections versus continuous subcutaneous insulin infusion therapy: a prospective 6-month study. Diabetes Care 2011;34:574-579

38. Beck RW, Riddlesworth T, Ruedy K, et al DIAMOND Study Group. Effect of continuous glucose monitoring on glycemic control in adults with type 1 diabetes using insulin injections: the DIAMOND randomized clinical trial. JAMA 2017 317:371-378

39. Huang ES, O'Grady M, Basu A, et al.; Juvenile Diabetes Research Foundation Continuous Glucose Monitoring Study Group. The cost-effectiveness of continuous glucose monitoring in type 1 diabetes. Diabetes Care 2010;33:1269-1274 40. McQueen RB, Ellis SL, Campbell JD, Nair KV, Sullivan PW. Cost-effectiveness of continuous glucose monitoring and intensive insulin therapy for type 1 diabetes. Cost Eff Resour Alloc 2011;9:13 41. Roze S, Saunders R, Brandt AS, de Portu S, Papo NL, Jendle J. Health-economic analysis of real-time continuous glucose monitoring in people with type 1 diabetes. Diabet Med 2015;32 618-626

42. Ly TT, Brnabic AJ, Eggleston A, et al. A costeffectiveness analysis of sensor-augmented insulin pump therapy and automated insulin suspension versus standard pump therapy for hypoglycemic unaware patients with type 1 diabetes. Value Health 2014;17:561-569

43. Roze S, Smith-Palmer J, Valentine WJ, et al. Long-term health economic benefits of sensoraugmented pump therapy vs continuous subcutaneous insulin infusion alone in type 1 diabetes: a U.K. perspective. J Med Econ 2016;19:236-242

44. Roze S, Smith-Palmer J, Valentine W, et al Cost-effectiveness of sensor-augmented pump therapy with low glucose suspend versus standard insulin pump therapy in two different patient populations with type 1 diabetes in France. Diabetes Technol Ther 2016;18:75-84

45. Beck RW, Riddlesworth TD, Ruedy K, et al. DIAMOND Study Group. Continuous glucose monitoring versus usual care in patients with type 2 diabetes receiving multiple daily insulin injections: a randomized trial. Ann Intern Med 2017; 167:365-374

46. Yoo HJ, An HG, Park SY, et al. Use of a real time continuous glucose monitoring system as a motivational device for poorly controlled type 2 diabetes. Diabetes Res Clin Pract 2008;82: 73-79

47. Vigersky RA, Fonda SJ, Chellappa M, Walker MS, Ehrhardt NM. Short- and long-term effects of real-time continuous glucose monitoring in patients with type 2 diabetes. Diabetes Care 2012 35:32-38

48. Carlson AL, Mullen DM, Bergenstal RM. Clinical use of continuous glucose monitoring in adults with type 2 diabetes. Diabetes Technol Ther 2017;19(Suppl. 2):S4-S11

49. Obermaier K, Schmelzeisen-Redeker G Schoemaker $M$, et al. Performance evaluations of continuous glucose monitoring systems: precision absolute relative deviation is part of the assessment. J Diabetes Sci Technol 2013;7:824832

50. Kovatchev BP, Patek SD, Ortiz EA, Breton MD Assessing sensor accuracy for non-adjunct use of continuous glucose monitoring. Diabetes Technol Ther 2015;17:177-186

51. Cryer PE. The barrier of hypoglycemia in diabetes. Diabetes 2008;57:3169-3176

52. Campbell MS, Schatz DA, Chen V, et al.; T1D Exchange Clinic Network. A contrast between children and adolescents with excellent and poor control: the T1D Exchange clinic registry experience. Pediatr Diabetes 2014;15:110-117

53. Lipska KJ, Warton EM, Huang ES, et al. $\mathrm{HbA}_{1}$ and risk of severe hypoglycemia in type 2 diabetes: the Diabetes and Aging Study. Diabetes Care 2013;36:3535-3542

54. Heller SR, Cryer PE. Reduced neuroendocrine and symptomatic responses to subsequent hypoglycemia after 1 episode of hypoglycemia in nondiabetic humans. Diabetes 1991;40:223-226

55. Davis MR, Mellman M, Shamoon H. Further defects in counterregulatory responses induced by recurrent hypoglycemia in IDDM. Diabetes 1992;41:1335-1340

56. Davis SN, Mann S, Galassetti P, et al. Effects of differing durations of antecedent hypoglycemia on counterregulatory responses to subsequent hypoglycemia in normal humans. Diabetes 2000 49:1897-1903

57. Öz G, Kumar A, Rao JP, et al. Human brain glycogen metabolism during and after hypoglycemia. Diabetes 2009;58:1978-1985 
58. Kovatchev BP, Cox DJ, Gonder-Frederick LA, Young-Hyman D, Schlundt D, Clarke W. Assessment of risk for severe hypoglycemia among adults with IDDM: validation of the low blood glucose index. Diabetes Care 1998;21:1870-1875 59. Fabris C, Patek SD, Breton MD. Are risk indices derived from CGM interchangeable with SMBG-based indices? J Diabetes Sci Technol 2015;10:50-59

60. Temelkova-Kurktschiev TS, Koehler C, Henkel E, Leonhardt W, Fuecker K, Hanefeld M. Postchallenge plasma glucose and glycemic spikes are more strongly associated with atherosclerosis than fasting glucose or $\mathrm{HbA}_{1 \mathrm{c}}$ level. Diabetes Care 2000;23:1830-1834

61. Haffner SM. Do interventions to reduce coronary heart disease reduce the incidence of type 2 diabetes? A possible role for inflammatory factors. Circulation 2001;103:346-347

62. Esposito K, Giugliano D, Nappo F, Marfella R; Campanian Postprandial Hyperglycemia Study Group. Regression of carotid atherosclerosis by control of postprandial hyperglycemia in type 2 diabetes mellitus. Circulation 2004;110:214-219 63. Monnier L, Mas E, Ginet C, et al. Activation of oxidative stress by acute glucose fluctuations compared with sustained chronic hyperglycemia in patients with type 2 diabetes. JAMA 2006;295: 1681-1687

64. Cox DJ, Kovatchev BP, Julian DM, et al. Frequency of severe hypoglycemia in insulin-dependent diabetes mellitus can be predicted from self-monitoring blood glucose data. J Clin Endocrinol Metab 1994;79:1659-1662

65. DeVries JH. Glucose variability: where it is important and how to measure it. Diabetes 2013;62:1405-1408
66. Hirsch IB. Glycemic variability and diabetes complications: does it matter? Of course it does! Diabetes Care 2015;38:1610-1614

67. Service FJ. Glucose variability. Diabetes 2013 62:1398-1404

68. Bergenstal RM. Glycemic variability and diabetes complications: does it matter? Simply put there are better glycemic markers! Diabetes Care 2015;38:1615-162

69. Rodbard D. The challenges of measuring glycemic variability. J Diabetes Sci Technol 2012;6:712-715 70. Kovatchev B, Cobelli C. Glucose variability: timing, risk analysis, and relationship to hypoglycemia in diabetes. Diabetes Care 2016;39:502-510 71. Reichard P, Pihl M. Mortality and treatment side-effects during long-term intensified conventional insulin treatment in the Stockholm Diabetes Intervention Study. Diabetes 1994;43:313-317

72. Kovatchev BP, Flacke F, Sieber J, Breton MD Accuracy and robustness of dynamical tracking of average glycemia (A1c) to provide real-time estimation of hemoglobin A1c using routine selfmonitored blood glucose data. Diabetes Technol Ther 2014;16:303-309

73. Egi M, Bellomo R, Stachowski E, French CJ, Hart G. Variability of blood glucose concentration and short-term mortality in critically ill patients. Anesthesiology 2006;105:244-252

74. Eslami S, Taherzadeh Z, Schultz MJ, AbuHanna A. Glucose variability measures and their effect on mortality: a systematic review. Intensive Care Med 2011;37:583-593

75. Qu Y, Jacober SJ, Zhang Q, Wolka LL, DeVries $\mathrm{JH}$. Rate of hypoglycemia in insulin-treated patients with type 2 diabetes can be predicted from glycemic variability data. Diabetes Techno Ther 2012;14:1008-1012
76. El-Laboudi AH, Godsland IF, Johnston DG, Oliver NS. Measures of glycemic variability in type 1 diabetes and the effect of real-time continuous glucose monitoring. Diabetes Technol Ther 2016;18:806-812

77. Monnier L, Colette C, Wojtusciszyn A, et al. Toward defining the threshold between low and high glucose variability in diabetes. Diabetes Care 2017;40:832-838

78. Rodbard D. Interpretation of continuous glucose monitoring data: glycemic variability and quality of glycemic control. Diabetes Technol Ther 2009;11(Suppl. 1):S55-S67

79. International Diabetes Center. AGP - Ambulatory Glucose Profile: AGP reports. Available from http://www.agpreport.org/agp/agpreports. Accessed 17 July 2017

80. Medtronic. New CareLink iPro Pattern Snapshot. Available from https://professional. medtronicdiabetes.com/para/new-carelink $₫$ iproß-pattern-snapshot-report. Accessed 29 August 2017

81. Dexcom. Dexcom CLARITY Diabetes Management Software. Available from https://www. dexcom.com/clarity. Accessed 29 August 2017

82. Bergenstal RM, Ahmann AJ, Bailey T, et al. Recommendations for standardizing glucose reporting and analysis to optimize clinical decision making in diabetes: the Ambulatory Glucose Profile (AGP). Diabetes Technol Ther 2013;15:198211

83. Xing D, Kollman C, Beck RW, et al.; Juvenile Diabetes Research Foundation Continuous Glu cose Monitoring Study Group. Optimal sampling intervals to assess long-term glycemic control using continuous glucose monitoring. Diabetes Technol Ther 2011;13:351-358 